\title{
Laminated Ti-Al composites: Processing, structure and strength
}

\author{
Du, Yan; Fan, Guohua; Yu, Tianbo; Hansen, Niels; Geng, Lin; Huang, Xiaoxu
}

Published in:

Materials Science and Engineering: A - Structural Materials: Properties, Microstructure and Processing

Link to article, DOI:

10.1016/j.msea.2016.07.108

Publication date:

2016

Document Version

Peer reviewed version

Link back to DTU Orbit

Citation (APA):

Du, Y., Fan, G., Yu, T., Hansen, N., Geng, L., \& Huang, X. (2016). Laminated Ti-Al composites: Processing, structure and strength. Materials Science and Engineering: A - Structural Materials: Properties, Microstructure and Processing, 673, 572-580. https://doi.org/10.1016/j.msea.2016.07.108

\section{General rights}

Copyright and moral rights for the publications made accessible in the public portal are retained by the authors and/or other copyright owners and it is a condition of accessing publications that users recognise and abide by the legal requirements associated with these rights.

- Users may download and print one copy of any publication from the public portal for the purpose of private study or research.

- You may not further distribute the material or use it for any profit-making activity or commercial gain

- You may freely distribute the URL identifying the publication in the public portal 


\title{
Laminated Ti-Al composites: processing, structure and strength
}

\author{
Y. Du ${ }^{1,2}$, G.H. Fan ${ }^{1}$, T. Yu², N. Hansen ${ }^{2}$, L. Geng ${ }^{1}$ and X. Huang ${ }^{2}$
}

1. School of Materials Science and Engineering, Harbin Institute of Technology, Harbin, 150001 Harbin, China

2. Danish-Chinese Center for Nanometals, Section for Materials Science and Advanced Characterization, Department of Wind Energy, Risø Campus, Technical University of Denmark, DK-4000 Roskilde, Denmark

\begin{abstract}
Laminated Ti-Al composite sheets with different layer thickness ratios have been fabricated through hot pressing followed by multi-pass hot rolling at $500^{\circ} \mathrm{C}$. The laminated sheets show strong bonding with an intermetallic interfacial layer of nanoscale thickness between the layers of $\mathrm{Ti}$ and $\mathrm{Al}$. The mechanical properties of the composites with different volume fraction of $\mathrm{Al}$ from $67 \%$ to $10 \%$ showed a good combination of strength and ductility. A constraint strain in the hot-rolled laminated structure between the 'hard' and 'soft' phases introduces an elastic-plastic deformation stage, more pronounced as the volume fraction of $\mathrm{Al}$ decreases. The thin intermetallic interfacial layer may also contribute to the strength of the composites. This effect increases with increasing volume fraction of the interface layer which thereby can contribute to the flow stress.
\end{abstract}

Keywords: Laminated composite; Hot rolling; Titanium; Aluminum; Mechanical properties

\section{Introduction}

Development of strong and light metals is an indefatigable pursuit of the goal [1-2] of sustainable, industrial development, and metallic materials are demanded with good ductility and toughness for processing such as shape forming. However, typically ductility and toughness of metals decrease with increasing strength. Composites may give the possibility of obtaining a good combination of strength and toughness, combined with impact and fracture resistance [3-5].

Metal composites have been investigated extensively with different morphology such as network $[6,7]$, gradient $[8,9]$, shell-core [10], and laminate [11, 12]. It has been found that controlling the distribution of reinforcement/matrix in composites could promote the potential of metal composites (including metal matrix composites and metal/metal composites) and realize configuration optimization. Laminated metal composite (LMC) is a simple model material and conventional mechanical properties of LMCs have been extensively studied since 1990s [13]. In general, the fracture strength of LMCs can be predicted based on the rule of mixture. However, an extra strengthening effect during an initial elastic-plastic stage may be considered, and the ductility diverges from prediction especially when the thicknesses and properties of component layers change [13-15]. In recent years, LMCs have attracted significant attention due to a good 
combination of ductility, strength and density, and also because of an excellent damping capacity utilized in light weight vehicles [16-18]. Multiple systems such as $\mathrm{Cu} / \mathrm{Nb}, \mathrm{Al} / \mathrm{Zn}$, and $\mathrm{Al} / \mathrm{Ti}$ fabricated by accumulative roll bonding (ARB) and asymmetric accumulative roll bonding (AARB) at room temperature have been investigated on both mechanical properties and microstructure evolution [19-21]. However, the stress states in bi-metallic sheets during rolling are complex and stress localization between component layers can lead to severe local necking in the LMCs. According to recent studies on LMCs by methods of hot rolling [22, 23] and hot pack rolling [24], the local shear of the component layers decreases with increasing rolling temperature, and our previous study [25] also proves that homogenous reduction of layer thickness can be obtained for laminated $\mathrm{Ti}-\left(\mathrm{SiC}_{\mathrm{p}} / \mathrm{Al}\right)$ composites by hot pressing followed by hot rolling.

Since $\mathrm{Ti}$ and $\mathrm{Al}$ are strong and light, respectively, it is important to study laminated $\mathrm{Ti}-\mathrm{Al}$ composites (LMCs) to fill a requirement of strong and light materials for automobile and aerospace industry. Hot-rolled laminated Ti-Al composites have been designed and fabricated in our previous study [26]. The interfaces of the hot-rolled laminated Ti-Al composites have been carefully characterized by SEM/EBSD, revealing that a rough interface creates heterogeneity, which affect the annealing behavior of the LMCs. The presence of interface layers between $\mathrm{Al}$ and $\mathrm{Ti}$ may also affect the mechanical properties, which is investigated in this study.

The LMCs with five different Ti/Al layer thickness ratios were fabricated using commercial purity $\mathrm{Ti}$ and $\mathrm{Al}$ sheets. The microstructure of these materials including the interfaces between $\mathrm{Ti}$ and $\mathrm{Al}$ layers were investigated, and the mechanical properties were examined by tensile tests. The data were analyzed to answer the following questions:

i) Do the LMCs have properties which point to further development for industrial applications;

ii) Can the experimental stress-strain behavior be modelled by applying the Rule of Mixture (ROM);

iii) In case of difference between ROM and the experiment, what can the cause(s) be?

2. Experimental methods

\subsection{Materials}

Commercial purity titanium TA1 sheets with a purity of 99.4 wt\% from Tianrui Non-ferrous Metal Co., Ltd. (Baoji, China), and commercial purity aluminum 1060 O sheet with a purity of 99.2 wt\% from Northeast Light Alloy Co., Ltd. (Harbin, China) were selected as starting materials. The chemical compositions and materials parameters are given in Table 1 and 2. Ti sheets with a thickness of $200 \mu \mathrm{m}$ and Al sheets with different thickness of $400 \mu \mathrm{m}, 200 \mu \mathrm{m}, 100 \mu \mathrm{m}, 50 \mu \mathrm{m}$ and $20 \mu \mathrm{m}$ were used as starting materials to produce hot-rolled laminated Ti-Al composites with 
different thickness ratio between $\mathrm{Ti}$ and $\mathrm{Al}$. All the sheets were cut into small pieces with a dimension of individual thickness in height and $100 \mathrm{~mm}$ square in size.

Table 1 Chemical compositions of the raw materials (wt.\%)

\begin{tabular}{ccccccccccccc}
\hline Materials & $\mathrm{Ti}$ & $\mathrm{Al}$ & $\mathrm{Fe}$ & $\mathrm{O}$ & $\mathrm{H}$ & $\mathrm{N}$ & $\mathrm{C}$ & $\mathrm{Si}$ & $\mathrm{Mn}$ & $\mathrm{Mg}$ & $\mathrm{Zn}$ & $\mathrm{Cu}$ \\
\hline TA1 & Bal. & - & 0.25 & 0.2 & 0.015 & 0.03 & 0.10 & 0.011 & - & - & - & - \\
\hline $1060 \mathrm{O}$ & - & Bal. & 0.35 & - & - & - & - & 0.25 & 0.03 & 0.03 & 0.05 & 0.05 \\
\hline
\end{tabular}

Table 2 Materials parameters of the raw materials

\begin{tabular}{cccccccc}
\hline Materials & $\begin{array}{c}\text { Density } \\
\left(\mathrm{g} / \mathrm{cm}^{3}\right)\end{array}$ & $\begin{array}{c}\text { Melting point } \\
\left({ }^{\circ} \mathrm{C}\right)\end{array}$ & $\begin{array}{c}\text { Elastic modulus } \\
(\mathrm{GPa})\end{array}$ & $\begin{array}{c}\text { Hardness } \\
(\mathrm{HV})\end{array}$ & $\begin{array}{c}\text { Tensile strength } \sigma_{\mathrm{b}} \\
(\mathrm{MPa})\end{array}$ & $\begin{array}{c}\text { Yield strength } \sigma_{0.2} \\
(\mathrm{MPa})\end{array}$ & $\begin{array}{c}\text { Elongation } \\
(\%)\end{array}$ \\
\hline TA1 & 4.5 & 1668 & 102 & 115.9 & 343 & 275 & 20 \\
\hline $1060 \mathrm{O}$ & 2.7 & 660 & 70 & 22.2 & 69 & 28 & 43 \\
\hline
\end{tabular}

\subsection{Fabrication process}

The hot-rolled LMCs were produced in three steps. i) Sheet preparation: the $\mathrm{Ti}$ and Al sheets were treated by 10 vol.\% HF and 10 vol.\% $\mathrm{NaOH}$, respectively, to remove contaminants and oxide layers from the surfaces. Then, the treated sheets were roughened with a steel brush, cleaned in an ultrasonic bath with acetone for $5 \mathrm{~min}$, and dried. ii) Diffusion bonding: the sheets were stacked alternately to about $6 \mathrm{~mm}$ in thickness with Ti sheets at the top and the bottom, put into a graphite die to confine the stack, and pressed at $500^{\circ} \mathrm{C}$ for $1 \mathrm{~h}$ under a pressure of $40 \mathrm{MPa}$ in a vacuum hot pressing furnace to obtain hot-pressed LMCs with a total thickness of about $6 \mathrm{~mm}$. iii) Hot rolling: The hot-pressed LMCs were hot rolled with a thickness reduction of $50 \%$ to about $3 \mathrm{~mm}$. The details of the rolling condition have been given elsewhere [26], and the schematic of the fabrication process is shown in the supplementary material 1 (S1). Materials parameters of the hot-rolled LMCs are shown in Table 3.

Table 3 The materials parameters of the hot-rolled laminated Ti-Al composites

\begin{tabular}{|c|c|c|c|c|c|c|c|c|}
\hline \multirow{2}{*}{ Materials } & \multicolumn{2}{|c|}{ Layer thickness $(\mu \mathrm{m})$} & \multicolumn{2}{|c|}{ Volume fraction (\%) } & \multirow{2}{*}{$\begin{array}{c}\text { Elastic Modulus } \\
\text { (GPa) }\end{array}$} & \multirow{2}{*}{$\begin{array}{c}\text { Thickness ratio } \\
\text { (Ti:Al) }\end{array}$} & \multirow{2}{*}{$\begin{array}{c}\text { Number of } \\
\text { interfaces between } \\
\text { Ti and Al }\end{array}$} & \multirow{2}{*}{$\begin{array}{l}\text { Total thickness } \\
\text { (mm) }\end{array}$} \\
\hline & $\mathrm{Ti}$ & $\mathrm{Al}$ & $\mathrm{Ti}$ & $\mathrm{Al}$ & & & & \\
\hline R200 & 100 & 200 & 33.3 & 66.7 & 80.7 & $1: 2$ & 10 & 2.8 \\
\hline R100 & 100 & 100 & 50.0 & 50.0 & 86.0 & $1: 1$ & 15 & 2.9 \\
\hline R50 & 100 & 50 & 66.7 & 33.3 & 91.3 & $2: 1$ & 18 & 2.7 \\
\hline R25 & 100 & 25 & 80.0 & 20.0 & 95.6 & $4: 1$ & 22 & 2.7 \\
\hline R10 & 100 & 10 & 90.9 & 9.1 & 99.1 & 10:1 & 25 & 2.7 \\
\hline
\end{tabular}

\subsection{Characterization}

The microstructure and texture of the hot-rolled LMCs were characterized by a scanning electron microscope (SEM, Zeiss Supra 35) equipped with an automated HKL electron backscatter diffraction (EBSD) facility. The sample surfaces for observation were the normal direction- 
transverse direction (ND-TD) planes. The samples were prepared by mechanical polishing for backscatter electron (BSE) imaging and electro polishing for EBSD mapping. The step size of EBSD data was $2 \mu \mathrm{m}$. A detailed study on the interface of the LMCs was made by a transmission electron microscopy (TEM, Tecnai G2 F30). The thin foil revealing the normal direction-rolling direction (ND-RD) section for TEM observation was prepared by an FEI HELIOS Nanolab 600i dual-beam workstation. Uniaxial tensile tests of the LMCs were carried out using an Instron-5569 universal testing machine. An extensometer was utilized with a gauge of $10 \mathrm{~mm}$. Dog bone shape tensile specimens of hot-rolled laminated Ti-Al composites had gauge dimensions of $18 \mathrm{~mm} \times 5$ $\mathrm{mm} \times 3 \mathrm{~mm}$. Dog bone shape tensile specimens of Ti and Al sheets, which had been under the same hot rolling condition as the LMCs were also prepared and tested. The thicknesses of $\mathrm{Ti}$ and $\mathrm{Al}$ sheets are $3 \mathrm{~mm}$ and $100 \mu \mathrm{m}$. A total of three specimens for each material conditions were tested at a constant crosshead speed of $2 \mathrm{~mm} / \mathrm{min}$ (corresponding strain rate of $1.8 \mathrm{E}^{-3} \mathrm{~s}^{-1}$ ). Both engineering stress/strain and true stress/strain curves were obtained from the database of the testing machine.

\section{Results}

\subsection{Mechanical properties of hot-rolled LMCs}

Fig. 1 shows tensile engineering stress-strain curves of the R100 (see Table 3) along the TD and the RD as an example. The yield strength (YS), ultimate tensile strength (UTS) and uniform elongation (UE) of the TD and RD samples are similar with values of 172MPa, $250 \mathrm{MPa}$ and 5.6\%, respectively. However, the total elongation (TE) of the TD samples is about $40 \%$, significantly higher than the elongation of the RD samples ( $30 \%)$. Therefore, TD was selected as the loading direction in the following tensile tests.

The tensile engineering stress-strain curves of individual hot-rolled $\mathrm{Al}$ and $\mathrm{Ti}$, and hot-rolled laminated Ti-Al composites (R200, R100, R50, R25 and R10) are shown in Fig. 2. The theoretical elastic module of the composites has been calculated by the Rule of Mixture (ROM) as shown in Table 3. The YS, UTS, TE, and UE have been obtained directly from the tensile curves, as the stress at $0.2 \%$ off-set, the maximum stress, the fracture strain and the strain at the maximum stress, respectively. These properties are given in Table 4 showing that: i) the YS and the UTS increases with decreasing Al layer thickness; ii) the YS of R10 and Ti are identical although R10 is expected to be lower; iii) the TE is 30 40\% for all the LMCs; iv) the UE is in the range of 5 6\% for LMCs with a volume concentration of $\mathrm{Al}$ from 33.3 to 66.7 vol.\%, but decreases to 3 5\% when the volume concentration of $\mathrm{Al}$ decreases to below 33.3\%. This combination of strength and ductility in the LMCs is interesting, as it widens the application potential of the composites to be discussed in 


\section{Section 5 .}

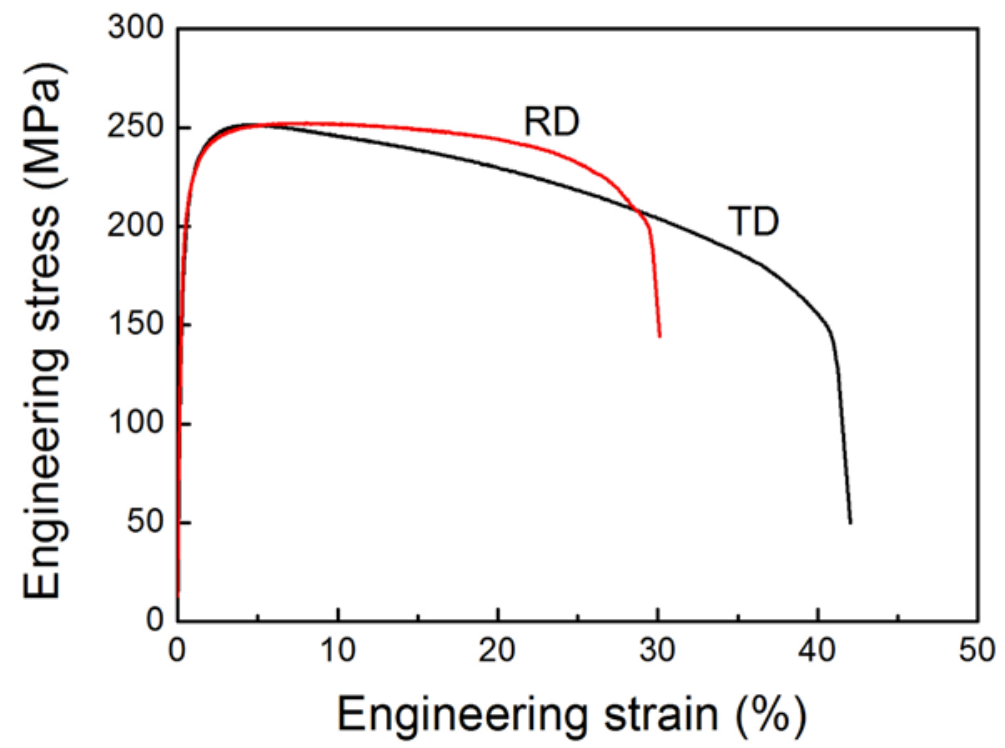

Fig. 1 Tensile engineering stress-strain curves of R100 tested in RD and TD

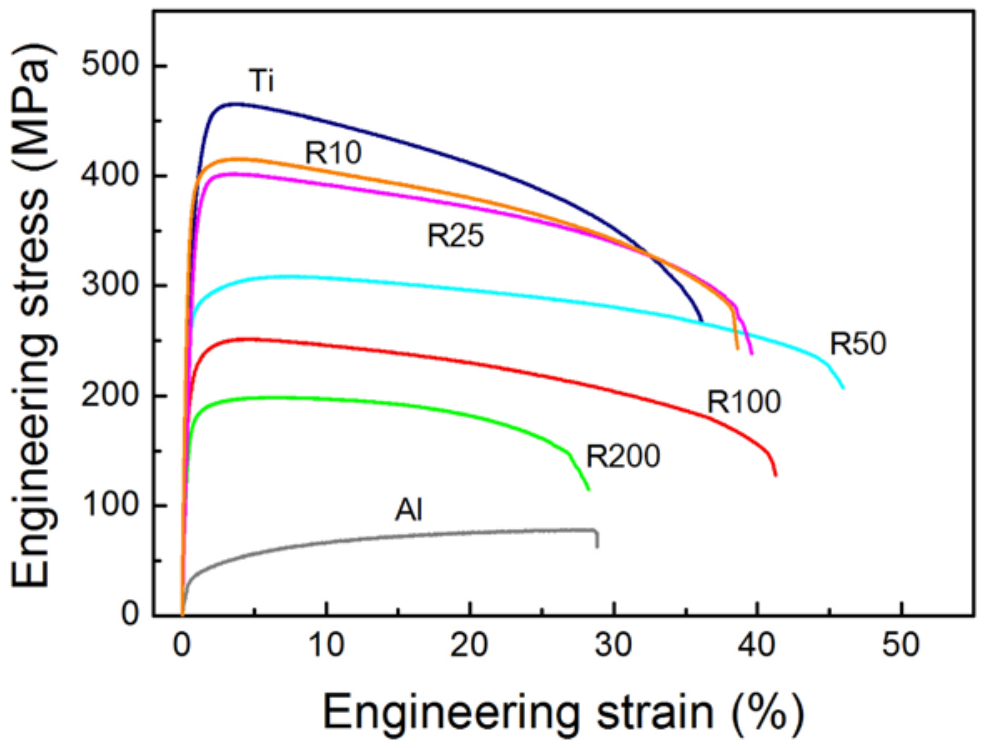

Fig. 2 Tensile engineering stress-strain curves of hot-rolled Ti and Al, and the LMCs (the loading direction is parallel to the TD)

The hardness of $\mathrm{Ti}$ and $\mathrm{Al}$ in different LMCs (R200, R100, R50, R25 and R10) was also measured. The hardness of Ti was independent on the thickness ratio with a mean value of $165 \mathrm{HV}$, whereas the hardness of $\mathrm{Al}$ was dependent on the thickness ratio (increasing values range from 28.5 HV 29.2 HV with decreasing Al layer thickness).

Table 4 The mechanical properties parameters of the hot-rolled individual $\mathrm{Ti}$ and $\mathrm{Al}$, and laminated Ti-Al composites (R200, R100, R50, R25 and R10) under loading direction parallel to the TD according to the engineering stress-strain curves 


\begin{tabular}{ccccc}
\hline Materials & YS (MPa) & UTS (MPa) & TE (\%) & UE (\%) \\
\hline $\mathrm{Ti}$ & $334.7 \pm 3.5$ & $456.4 \pm 8.7$ & $35.9 \pm 0.6$ & $3.2 \pm 0.4$ \\
\hline $\mathrm{Al}$ & $13.8 \pm 0.4$ & $78.4 \pm 5.3$ & $30.5 \pm 2.3$ & $25.8 \pm 0.3$ \\
\hline $\mathrm{R} 200$ & $124.9 \pm 1.5$ & $198.3 \pm 0.3$ & $30.0 \pm 5.5$ & $5.3 \pm 0.1$ \\
\hline $\mathrm{R} 100$ & $171.9 \pm 1.4$ & $250.3 \pm 4.8$ & $40.2 \pm 2.1$ & $5.6 \pm 0.3$ \\
\hline $\mathrm{R} 50$ & $227.7 \pm 2.1$ & $310.8 \pm 2.2$ & $42.5 \pm 3.7$ & $5.7 \pm 0.2$ \\
\hline $\mathrm{R} 25$ & $295.3 \pm 2.4$ & $402.7 \pm 0.1$ & $39.4 \pm 0.4$ & $3.5 \pm 0.1$ \\
\hline $\mathrm{R} 10$ & $334.9 \pm 3.2$ & $415.7 \pm 7.2$ & $39.1 \pm 0.9$ & $3.5 \pm 0.2$ \\
\hline
\end{tabular}

\subsection{Microstructure of the hot-rolled LMCs}

The microstructure of the LMCs was examined by SEM. Fig. 3(a) shows an example of BSE image of a composite with a Ti/Al thickness ratio 1:1. BSE images of samples R200, R100, R50, R25 and R10 are shown as Fig. 3(b)-(f). The interface between Ti and Al layers is flat after hot pressing but become rough after hot rolling, but no reaction layer between $\mathrm{Al}$ and $\mathrm{Ti}$ was found. The $\mathrm{Ti}$ and $\mathrm{Al}$ layers deformed uniformly under the multi-pass hot rolling and no local necking occurred as shown in Fig. 3. Microstructure and texture for R100 were characterized by EBSD as shown in Fig. 4. Fig. 4(a) shows the deformed microstructure. The Ti layers show a strong <0002>//ND preferred orientation according to the inverse pole figure as inset in Fig. 4(a), and the pole figures show a Ti basal plane texture in Fig. 4(c). As shown in Fig. 4(b), a large region of Al layers observed by EBSD reveals that the crystallographic orientation in the Al layers is random.

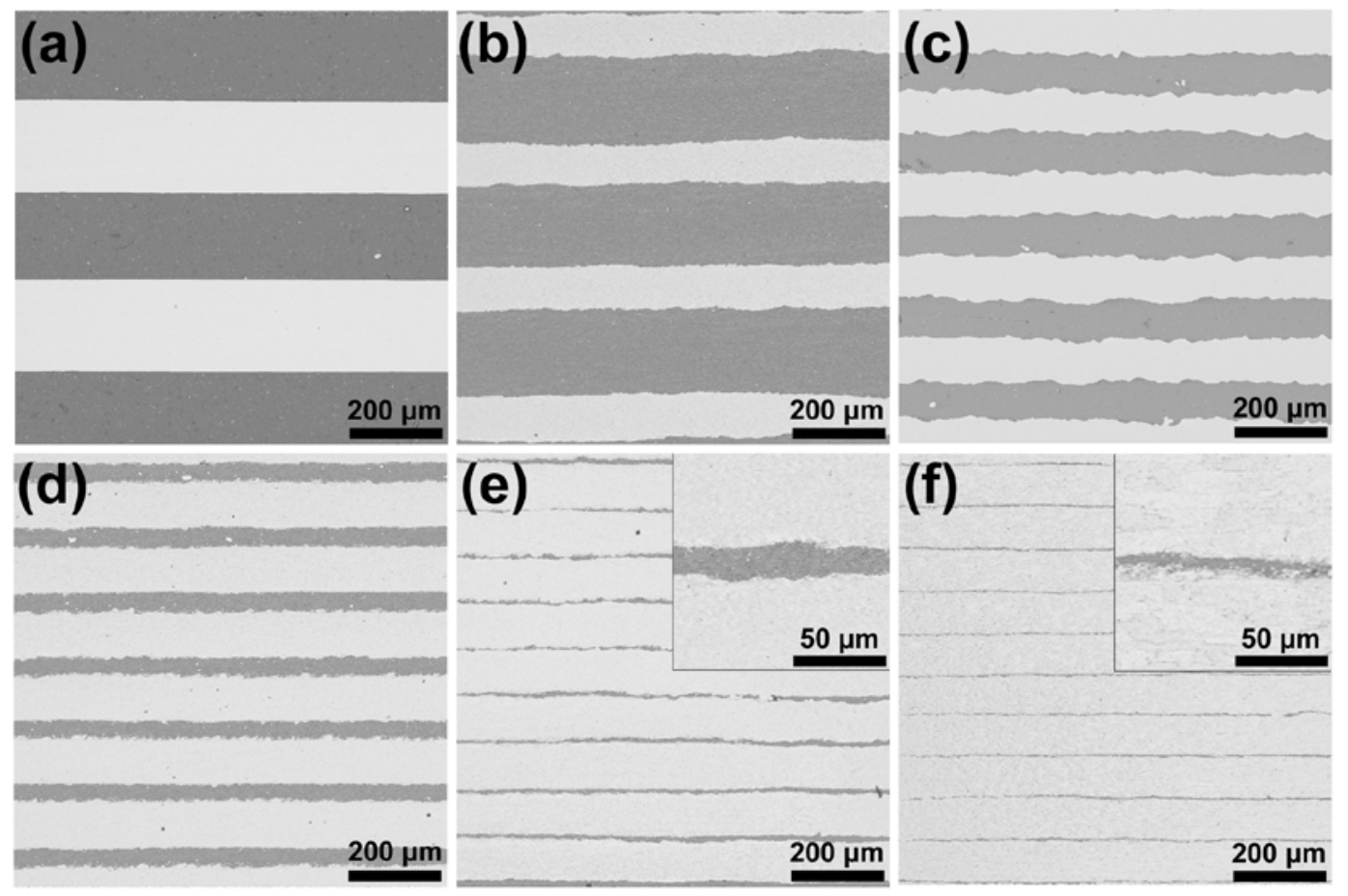

Fig. 3 BSE images of the ND-TD section of hot-pressed and hot-rolled LMCs: (a) hot-pressed Ti-Al with both Ti and Al layer thickness of $200 \mu \mathrm{m}$; (b) R200; (c) R100; (d) R50; (e) R25 (high magnification image in inset); (f) R10 (high 
magnification image in inset), showing that $\mathrm{Ti}$ and $\mathrm{Al}$ deform uniformly and that flat interfaces after hot pressing become rough after hot rolling
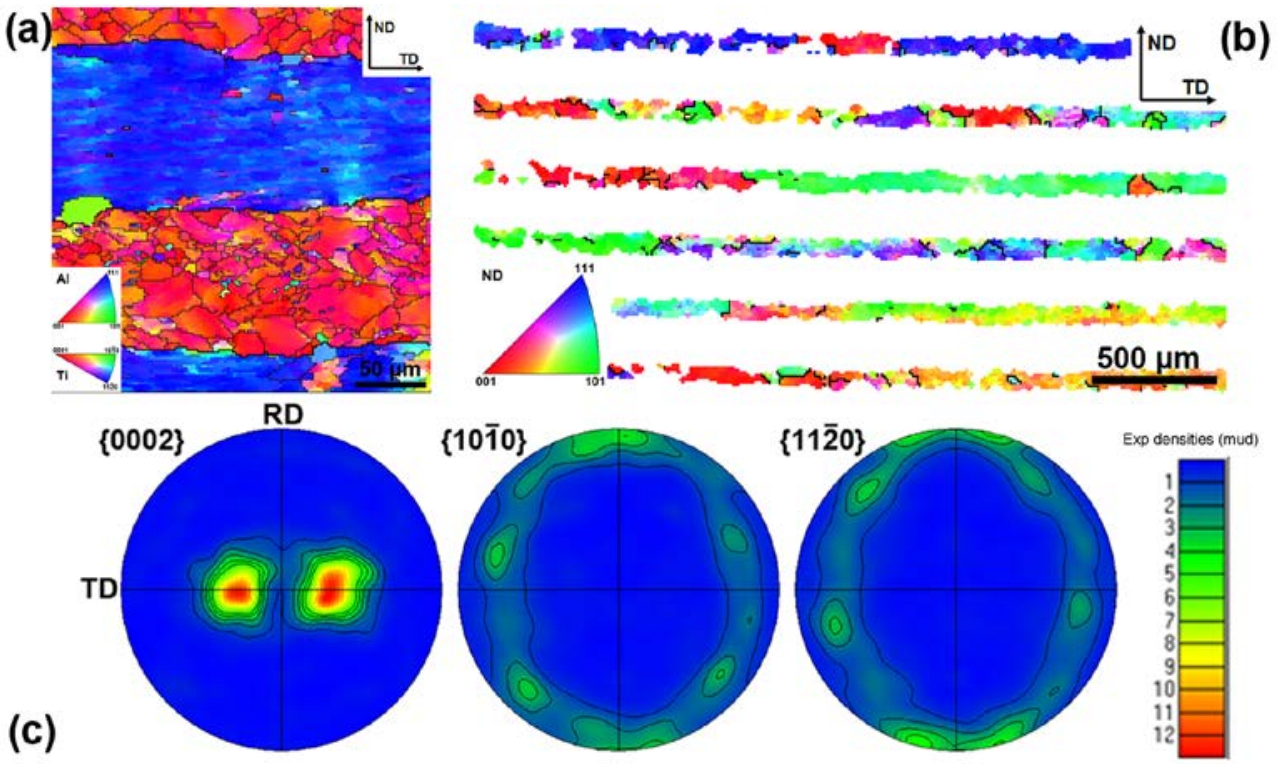

Fig. 4 An example of microstructure and texture of the LMCs (R100): (a) EBSD map of R100 (inverse pole figure of the ND); (b) EBSD map of Al layers (inverse pole figure of the ND); (c) pole figures of the Ti layer

The microstructure of R100 observed by TEM is shown in Fig. 5 for Al 5(a) and Ti 5(b). Both structures are subdivided by dislocation cell boundaries and sub-grain boundaries with some dislocation and dislocation tangles between the boundaries. The structural scale is compared in $\mathrm{Ti}$ and $\mathrm{Al}$ with a boundary spacing of $1 \mu \mathrm{m}$ and $2 \mu \mathrm{m}$, respectively. Taking into account with the melting point of $\mathrm{Al}\left(660^{\circ} \mathrm{C}\right)$ and $\mathrm{Ti}\left(1668{ }^{\circ} \mathrm{C}\right)$, the microstructure could be characterized as a typical hot deformed and warm deformed structure, respectively. The microstructure of the interface region between $\mathrm{Al}$ and $\mathrm{Ti}$ between $\mathrm{Al}$ and $\mathrm{Ti}$ has been discussed in more detail in our previous study [26]. It was demonstrated that interface roughness developed during the rolling due to different properties of the grains in $\mathrm{Ti}$ and $\mathrm{Al}$. Protrusions and retrusions are formed along the interface introducing areas of strain localization in the $\mathrm{Al}$ layer near the Ti-Al interface.

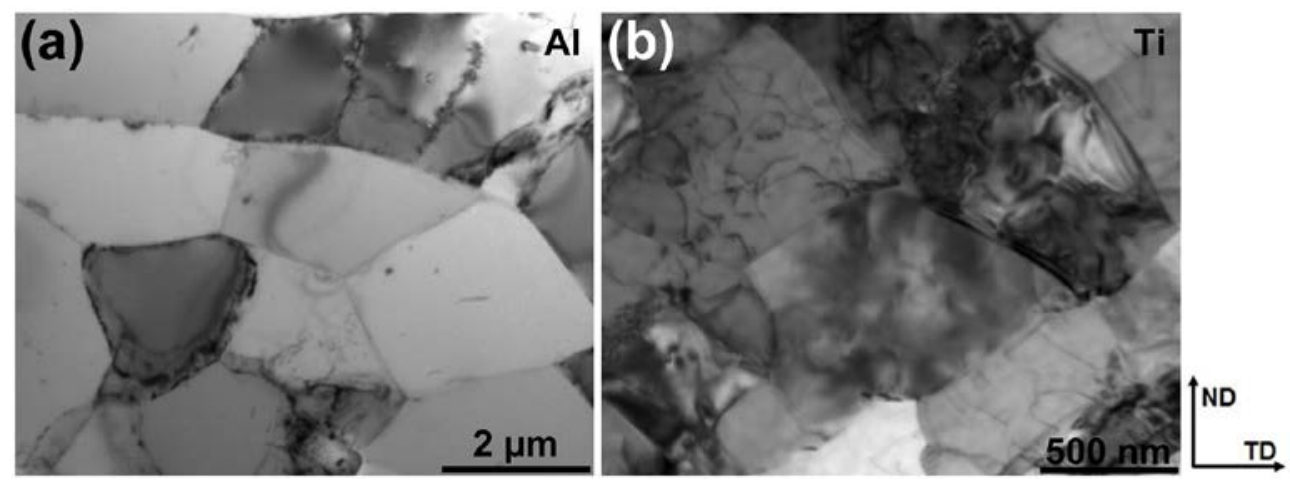

Fig. 5 Microstructure of $\mathrm{Al}$ and Ti in a LMC (R100) observed by TEM: (a) $\mathrm{Al}$ and (b) Ti. The microstructure is 
subdivided by sub-grain boundaries and dislocation cell boundaries (see text).

\subsection{Interface in the hot-rolled LMC}

Detailed TEM investigations were carried out to study the interface in the LMCs. Fig. 6 shows the TEM micrographs at the interface of R100 as an example. Based on the micro-diffraction pattern, the $\mathrm{TiAl}_{3}$ phase with a $\mathrm{DO}_{22}$ structure was found as the interface between $\mathrm{Al}$ and Ti. The thickness of the interfacial intermetallic phase was about $100 \mathrm{~nm}$.

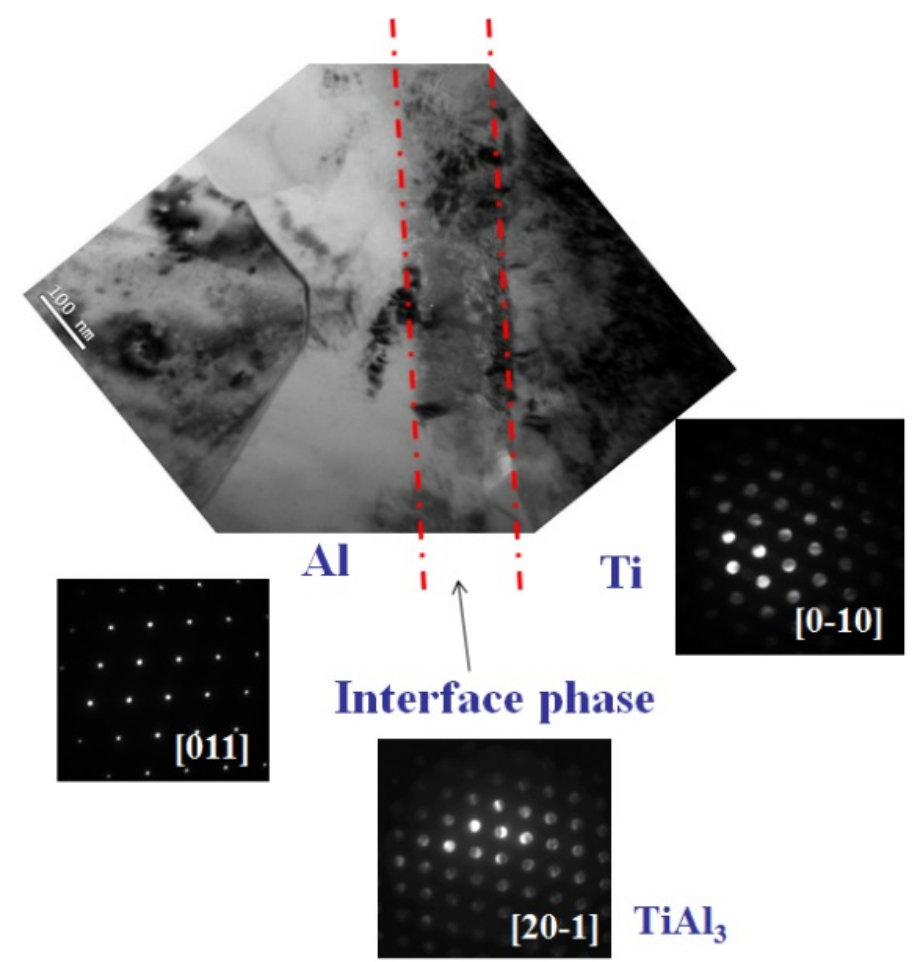

Fig. 6 Microstructure of LMC (R100) observed by TEM (bright field, selected area diffraction and micro-diffraction), showing $\mathrm{TiAl}_{3}$ interfacial layer with a thickness about $100 \mathrm{~nm}$ between $\mathrm{Ti}$ and $\mathrm{Al}$ layers

A line in a TEM through the interface of the LMC from Al to Ti marked by a red line with an arrow is shown in Fig. 7(a). This line scanning shows a gradient of diffusion and formation of $\mathrm{TiAl}_{3}$ in Fig. 7(b). Ti and Al started to diffuse during hot pressing, and it continues during multipass hot rolling. $\mathrm{TiAl}_{3}$ has a lower Gibbs free energy compared to $\mathrm{TiAl}$ and $\mathrm{Ti}_{3} \mathrm{Al}$ according to thermodynamic calculation presented in [27], which leads to formation of the $\mathrm{TiAl}_{3}$ layer. Interface layers of the other samples showed that the thickness of the intermetallic interface is nearly the same, demonstrating that the formation of the intermetallic phase is independent of the thickness ratio. However, the thickness of the intermetallic layer can be controlled by choosing hot-rolling conditions including number of rolling passes, thickness reduction and rolling temperature, which is for future research and development (see outlook). 

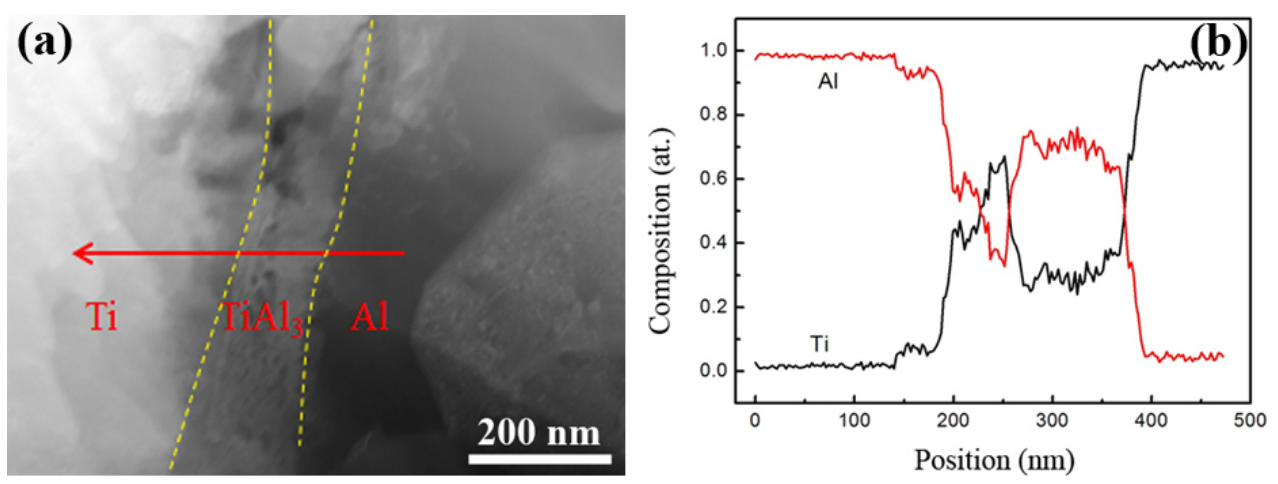

Fig. 7 The line scanning result at the interface region of a LMC observed by TEM: (a) microstructure in STEMHAADF mode with $\mathrm{TiAl}_{3}$ interface marked by yellow dash lines and red arrow representing the scanning direction and position; (b) composition gradient distribution of the LMC corresponding to the red line marked with an arrow in (a)

\section{Modelling}

\subsection{Rule of Mixture}

The strength of the composites can be estimated applying ROM [13, 15]. According to the hardness of $\mathrm{Ti}$ and $\mathrm{Al}$ layers in the LMCs, their individual flow stress does not change significantly with thickness ratio. Thus, the tensile stress-strain behavior of the composites can be calculated based on the tensile stress-strain curves of hot-rolled $\mathrm{Ti}$ and $\mathrm{Al}$. In this case, the analysis requires: i) the tensile stress-strain curves of hot-rolled $\mathrm{Ti}$ and $\mathrm{Al}$, and ii) the volume fraction of $\mathrm{Ti}$ and $\mathrm{Al}$. The application of the ROM has been based on the following assumptions:

i) The deformation is uniform throughout the composite and the elastic/plastic strain of $\mathrm{Ti}$ and $\mathrm{Al}$ are identical to the external strain during deformation, i.e $\varepsilon_{T i}=\varepsilon_{A l}=\varepsilon$.

ii) The strength of Ti in the LMCs is identical to that of hot-rolled Ti with a thickness reduction of $50 \%$. The flow stress of $\mathrm{Ti}$ is measured up to a strain corresponding to the UTS, at larger strains the work hardening rate is negligible and the flow stress is taken to be constant.

iii) The strength of $\mathrm{Al}$ in the LMCs is identical to that of hot-rolled $\mathrm{Al}$ with a thickness reduction of $50 \%$, and the tensile behavior of the $\mathrm{Al}$ foil is assumed to be independent of the thickness.

Based on the above idealized assumptions, the flow stress of the composites with different layer thickness ratio at a given strain can be obtained on the basis of the ROM:

$$
\sigma=\sigma_{T i} \cdot v_{T i}+\sigma_{A l} \cdot v_{A l}
$$

and

$$
v_{T i}+v_{A l}=1
$$

where $\sigma$ is the flow stress of the composite, $\sigma_{T i}$ and $\sigma_{A l}$ are the flow stresses of hot-rolled $\mathrm{Ti}$ and $\mathrm{Al}$, $v_{T i}$ and $v_{A l}$ are the volume fraction of $\mathrm{Ti}$ and $\mathrm{Al}$ as shown in Table 3. The flow stresses is obtained from the true stress-strain curves of $\mathrm{Ti}$ and $\mathrm{Al}$ at given strains shown in Fig. 8(a). The dashed line 
for $\mathrm{Ti}$ is illustrated the assumption of a constant flow stress. A tensile flow curve can be obtained corresponding to successive strains and the work hardening rate can be calculated by differentiating the flow curve, see Fig. 8(a) for R100 as an example. The calculated uniform strain $\varepsilon_{\mathrm{u}}$ can be determined according to the Considére criterion [28], as the strain where the work hardening rate $\Theta$ equals to the stress $\sigma$, see Fig. 8(a). This stress is taken to be the UTS. It worth noting that both Al and Ti continue to work hardening during plastic deformation until the work hardening rate reaches zero or the specimen fails. The calculated true tensile curves (up to a strain of 0.05) of the LMCs with different layer thickness ratio are shown in Fig. 8(b). The calculated strength of the composites increases with decreasing volume fraction of $\mathrm{Al}$ at all strains. The calculated mechanical properties parameters are shown in Table 5, compared with the experimental properties from Table 4. For the YS, the true stress of experimental result is defined as the same with the engineering stress due to very low area reduction in cross-section. The comparison shows good agreement between experimental and calculated results using ROM for R200, R100 and R50, variation for ROM is found for R25 and R10. For the UTS, the experimental result is the true stress (considering an area reduction in cross-section) at the UE (see Table 4). The comparison shows less variation (percentage) than YS. It worth noting that strain under 0.05 is the main region for our research on strengthening mechanism in the LMCs.
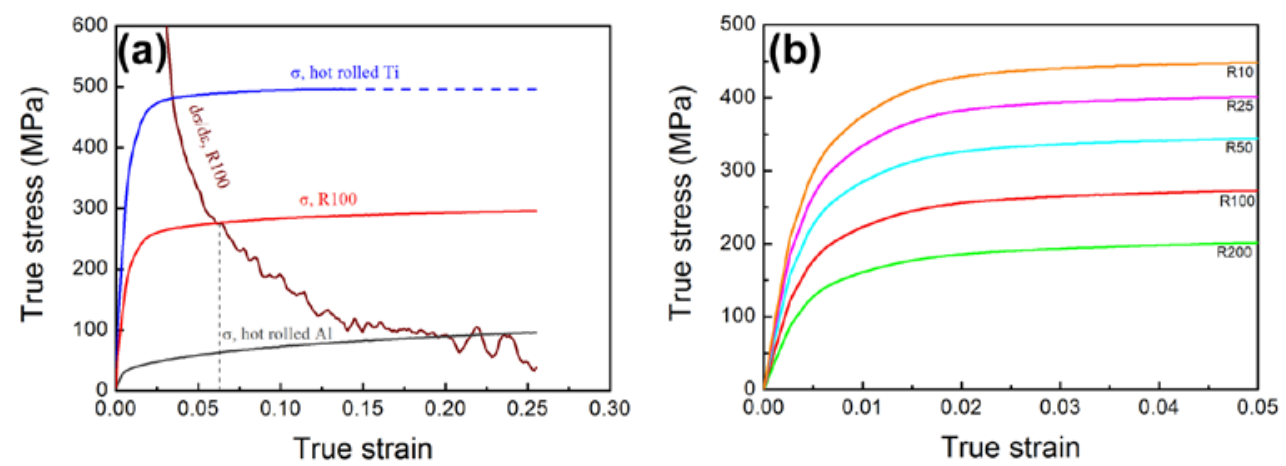

Fig. 8 Calculated tensile curves of the LMC based on the ROM: (a) an example showing calculated tensile curve of R100 based on tensile curves of hot-rolled $\mathrm{Ti}$ and $\mathrm{Al}$, the intersection between the calculated tensile curve and work hardening curve corresponds to the uniform strain $\varepsilon_{\mathrm{u}}$ and the UTS; (b) calculated tensile curves of the LMCs

Table 5 Comparison between calculated and experimental mechanical properties of the LMCs

\begin{tabular}{ccccccc}
\hline Materials & YS $_{\mathbf{C}}$ (MPa) & YS $_{\text {E }}$ (MPa) & $\boldsymbol{\Delta}_{\text {Ys }}$ (MPa) & UTS $_{\mathbf{C}}$ (MPa) & UTS $_{\text {E }}$ (MPa) & $\boldsymbol{\Delta}_{\text {UTS }}$ (MPa) \\
\hline R200 & 120.7 & 124.9 & 4.2 & 204.4 & 208.8 & 4.4 \\
\hline R100 & 174.2 & 171.9 & -2.3 & 267.4 & 264.3 & -3.1 \\
\hline R50 & 227.2 & 227.7 & 0.5 & 330.4 & 328.5 & -1.9 \\
\hline R25 & 270.5 & 295.3 & 24.8 & 396.3 & 416.8 & 20.5 \\
\hline R10 & 305.5 & 334.9 & 29.4 & 422.1 & 430.2 & 8.1 \\
\hline
\end{tabular}




\subsection{Variation from Rule of Mixture}

The variation from ROM is significant for R25 and R10, whereas ROM shows good agreement with experimental results for LMCs with thicker Al layers and higher volume concentration of $\mathrm{Al}$. These variations may have different causes where two will be discussed in the following. We previously explained that the interface after hot deformation is rough with protrusions and retrusions. This roughness may introduce some strain incomparability but the effect and strength is assumed to be small. A more significant effect is expected from two other strengthening mechanisms, which increase the experimental strength above ROM. These mechanisms relate to: (i) the formation of an interface reaction layer between $\mathrm{Ti}$ and $\mathrm{Al}$, and (ii) a constraint effect due to different elastic/plastic behavior of Ti/Al.

\subsubsection{Interface reaction layer}

Since nanoscale intermetallic phase of $\mathrm{TiAl}_{3}$ forms as layer at the interface, the strength of $\mathrm{TiAl}_{3}$ should also be considered when calculating the strength of the LMCs, therefore, when calculating the mechanical properties two aspects have to be considered: i) an effect of the interface layer of $\mathrm{TiAl}_{3}$ and ii) an effect of a chemical diffusion region in the $\mathrm{Ti}$ and $\mathrm{Al}$ layers.

The thickness of the $\mathrm{TiAl}_{3}$ is a constant with average value of $100 \mathrm{~nm}$. Since the volume fraction of interface phase $\left(\mathrm{TiAl}_{3}\right)$ can be calculated as:

$$
v_{T i A l_{3}}=\frac{d_{T_{i A l_{3}}}}{d}
$$

where $d_{\mathrm{TiAl}_{3}}$ and $d$ are the total thicknesses of the $\mathrm{TiAl}_{3}$ layers and the LMC, respectively. A modified rule of mixture (MROM), the strength of the LMC is therefore suggested as following:

$$
\sigma_{M R O M}=\sigma_{\mathrm{TiAl}_{3}} \cdot v_{\mathrm{TiAl}_{3}}+\sigma_{\text {cal.(Ti-Al) }} \cdot v_{\mathrm{Ti}-\mathrm{Al}}
$$

where $v_{T i-A l}$ and $v_{T i A l}$ are the volume fractions of $\mathrm{Ti}$ and $\mathrm{Al}$ layers and $\mathrm{TiAl}_{3}$ layers, respectively; $\sigma_{\text {cal.(Ti-Al) }}$ is the strength of the LMC calculated by the rule of mixture assuming that there is no intermetallic phase in the LMC; $\sigma_{T i A l}$ is the strength of $\mathrm{TiAl}_{3}, \sigma_{M R O M}$ is the strength of the LMC with an interface present. Since the failure stress of bulk $\mathrm{TiAl}_{3}$ is around $600 \mathrm{MPa}$ with large variation due to the brittle nature of $\mathrm{TiAl}_{3}$ [29], the strength of $\mathrm{TiAl}_{3}$ in the $\mathrm{LMC}$ is calculated based on our previous study [30], showing that a $\mathrm{TiAl}_{3}$ layer with a thickness of $5 \mu \mathrm{m}$ had an elastic module of $220 \pm 10 \mathrm{GPa}$ measured by nanoindentation. As $\mathrm{TiAl}_{3}$ is very thin layer in the LMC, $\sigma_{\mathrm{TiAl}}$ is assumed to be as high as $6600 \pm 300 \mathrm{MPa}$ based on an assumption of elastic deformation of $\mathrm{TiAl}_{3}$ to a strain of 0.03 . Thus, a variation between the MROM and ROM is expected, and this variation will increase with decreasing $\mathrm{Al}$ layer thickness due to increasing volume fraction of $\mathrm{TiAl}_{3}$. 
Contributions of $\mathrm{TiAl}_{3}$ in the LMCs have been calculated as shown in Table 6, assuming that the strength of $\mathrm{TiAl}_{3}$ is $6600 \pm 300 \mathrm{MPa}$ as mentioned above. It worth noting that the strength of $\mathrm{TiAl}_{3}$ should be lower than $6600 \mathrm{MPa}$, thereby the actual contribution of $\mathrm{TiAl}_{3}$ is smaller than the estimation. Thus, the interface reaction layer produces small variation for ROM.

Table 6 Contribution estimation of $\mathrm{TiAl}_{3}$ layers

\begin{tabular}{ccc}
\hline Materials & Volume fraction of TiAl $_{3}$ & Contribution of TiAl $_{3}$ (MPa) \\
\hline R200 & 0.00036 & $2.38 \pm 0.11$ \\
\hline R100 & 0.00052 & $3.43 \pm 0.16$ \\
\hline R50 & 0.00068 & $4.49 \pm 0.20$ \\
\hline R25 & 0.00081 & $5.35 \pm 0.24$ \\
\hline R10 & 0.00091 & $6.01 \pm 0.27$ \\
\hline
\end{tabular}

\subsubsection{Constraint effect}

Due to different elastic/plastic properties of $\mathrm{Al}$ and $\mathrm{Ti}$, a constraint effect is expected to be developed when the LMC is strained in tension. In a first stage, both phases deform elastically. At a higher strain, $\mathrm{Al}$ can deform plastically while Ti continues to be elastically deformed. Finally, in a third stage, both $\mathrm{Al}$ and $\mathrm{Ti}$ deform plastically. In the second stage, a misfit strain increases with the tensile strain and this misfit strain gives rise to an elastic strain which may be relaxed by formation of geometrically necessary dislocations [31]. These dislocations will strengthen the Al phase i.e. its contribution to the strength of the composites will increase. As $\mathrm{Al}$ is constrained between the harder Ti layers, it must be expected that the constraint effect will in increase with decreasing thickness of the Al layers. The constraint effect is illustrated in Fig. 9, showing that is significantly larger in R10 than in R100 as expected. It also shows that this contribution to the composite strength is exhausted at a strain of about 0.015 . At higher strains ROM will then be applicable.

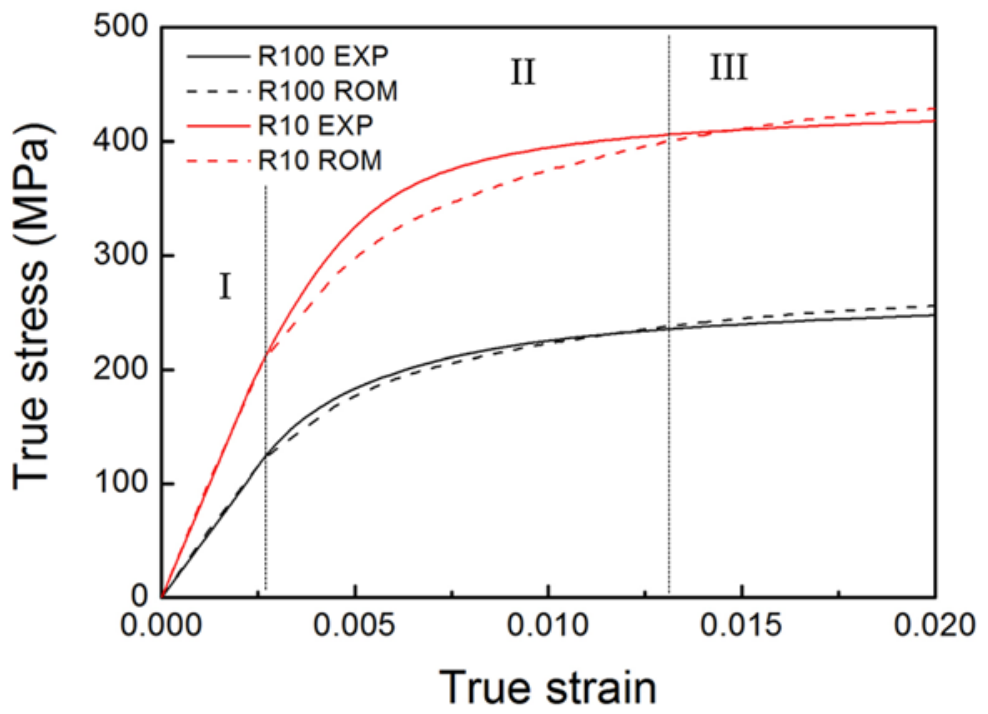


Fig. 9 Comparison between experimental and calculated results based on the ROM of the LMCs (R100 and R10 along the TD)

5. Optimization of the mechanical properties of LMCs

LMC is an engineering material. The development of the LMC of Ti and Al therefore has an objective to develop a strong and light metallic material for applications in the automobile and aerospace industry. Many properties are important but three will be discussed: i) The strength which has been shown to be significantly dependent on the thickness ratio between $\mathrm{Ti}$ and $\mathrm{Al}$ offering a possibility of materials design based on properties of both materials and application of ROM (Composite examples of R200, R100 and R50). ii) Ductility and formability are promising when taken into account and the total elongation for all the composites is 30 40\% similar to $\mathrm{Ti}$ and $\mathrm{Al}$. Also important is the uniform elongation which is 5 6\% for R200, R100 and R50. iii) Weight which is reduced as the application of $\mathrm{Al}$ with a low density will decrease the weight per unit of the composites. An important parameter is the specific strength:

$$
\sigma_{\text {specific }}=\frac{\sigma}{\rho}
$$

where $\rho$ is the density. For $\rho$ and the specific yield strength (SYS) and ultimate tensile strength (SUTS) are given in Table 7. Since the volume fraction of $\mathrm{TiAl}_{3}$ is very low, the results were calculated based on experimental results in Table 4 based on the universal ROM. The specific strengths for the five LMCs are given in Fig. 10 together with the uniform elongation. Values for Ti are also included. This figure illustrate that a good combination of properties is obtained from a percentage of $\mathrm{Al}$ in the range of 33 66\%. The best specific strength is obtained for R25 and R10 with a percentage of $\mathrm{Al}$ in the range up to $20 \%$. The uniform elongation is low but it is combined with a high total elongation which may have a beneficial effect when formability is evaluated, which is part of the ongoing investigation.

Table 7 Tensile specific strengths of the hot-rolled laminated Ti-Al composites

\begin{tabular}{cccc}
\hline Materials & SYS (Nm/Kg) & SUTS $(\mathbf{N m} / \mathbf{K g})$ & $\mathbf{\rho}\left(\mathbf{g} \cdot \mathbf{c m}^{-3}\right)$ \\
\hline R200 & 0.038 & 0.060 & 3.30 \\
\hline R100 & 0.048 & 0.070 & 3.60 \\
\hline R50 & 0.058 & 0.080 & 3.90 \\
\hline R25 & 0.071 & 0.097 & 4.14 \\
\hline R10 & 0.077 & 0.096 & 4.33 \\
\hline
\end{tabular}




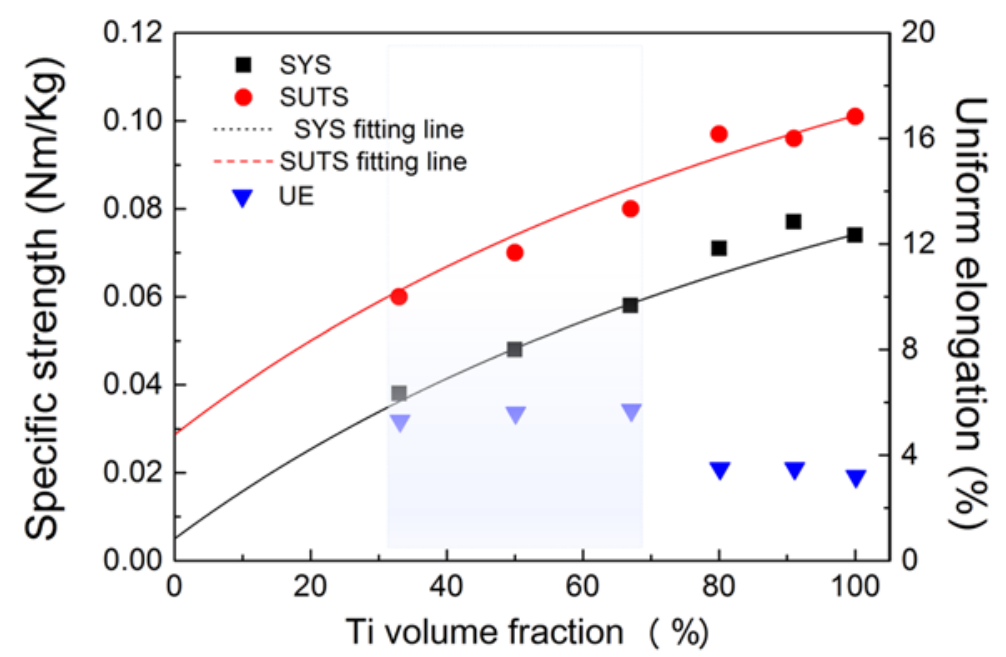

Fig. 10 Comparisons of the experimental results of specific strength of hot-rolled laminated Ti-Al composites with the ideal simulation result according to the properties of component materials

6. Conclusions and outlook

Laminated Ti-Al composites (LMCs) have been fabricated by hot pressing followed by multipass hot rolling at $500^{\circ} \mathrm{C}$. The LMCs are fully dense and show a property combination of strength, ductility and density. Potential application is in the automobile and aerospace industries. The key parameter is the $\mathrm{Ti} / \mathrm{Al}$ layer thickness ratio and the conclusions are the following:

For a layer thickness of Al larger than $25 \mu \mathrm{m}$ (Al $20 \mathrm{vol} \%$ ), the stress-strain curves can be modelled from Rule of Mixture (ROM).

For layer thickness of $\mathrm{Al}$ at $25 \mu \mathrm{m}$ and below, ROM under predict the flow stress with about $10 \%$ and the stress-strain curves show an elastic-plastic stage followed by plastic deformation.

Causes of the ROM underprediction have been identified as following in increasing order of importance: i) roughness of the $\mathrm{Ti} / \mathrm{Al}$ interface, ii) interface reaction between $\mathrm{Al}$ and $\mathrm{Ti}$, iii) evolution of constraint strain.

In an outlook, it is suggested to optimize the LMC design by replacing the pure metals with alloys and by expending formability studies for applications of LMC. The constraint strain effect will in further studies be investigated by transmission electron microscopy and high energy X-ray in a synchrotron.

\section{Acknowledgement}

The authors gratefully acknowledge the financial support from the National Natural Science Foundation of China (Grant No. 51571070, 51571071), the Scientific Research Foundation for the Returned Overseas Chinese Scholars, State Education Ministry and the Danish National Research 
Foundation (Grant No. DNRF86-5). Author Y.D. also gratefully acknowledges the financial support from China Scholarship Council (Grant No. 201406120134).

\section{References}

[1] Cole GS, Sherman AM. Light weight materials for automotive applications. Mater Charact 1995; 35(1): 3-9.

[2] Shi J, Sun X, Wang M, Hui W, Dong H, Cao W. Enhanced work-hardening behavior and mechanical properties in ultrafine-grained steels with large-fractioned metastable austenite. Scr Mater 2010; 63: 815-818.

[3] Tanaka K, Mori T. The hardening of crystals by non-deforming particles and fibres. Acta Metall 1970, 18: 931939.

[4] Ortiz C, Boyce MC. Bioinspired structural materials. Science 2008; 319: 1053-1054.

[5] Chaudhari GP, Acoff V. Cold roll bonding of multi-layered bi-metal laminate composites. Compos Sci Technol 2009; 69: 1667-1675.

[6] Huang LJ, Wang S, Dong YS, Zhang YZ, Pan F, Geng L, Peng HX, Tailoring a novel network reinforcement architecture exploiting superior tensile properties of in-situ TiBw/Ti composites. Mater Sci Eng A 2012; 545: 187-193.

[7] Peng HX, Fan Z, Evans JRG. Bi-continuous metal matrix composites. Mater Sci Eng A 2001; 303: 37-45.

[8] Pan QS, Lu QH, Lu L. Fatigue behavior of columnar-grained Cu with preferentially oriented nanoscale twins. Acta Mater 2013; 61: 1383-1393.

[9] Liu XC, Zhang HW, Lu K. Strain-induced ultrahard and ultrastable nanolaminated structure in nickel. Science 2013; 342: 337-340.

[10] Wei YJ, Li YQ, Zhu LC, Liu Y, Lei XQ, Wang G, Wu XY, Mi ZL, Liu JB, Wang HT, Gao HJ. Evading the strength-ductility trade-off dilemma in steel through gradient hierarchical nanotwins. Nat Commun 2014; 5: 3580-3587.

[11] Deville S, Saiz E, Nalla RK, Tomsia AP. Freezing as a path to build complex composites. Science 2006; 311: 515-518.

[12] Launey ME, Munch E, Alsem DH, Saiz E, Tomsia AP, Ritchie RO. A novel biominetic approach to the design of high-performance ceramic-metal composites. J R Soc Interface 2010; 7: 741-753.

[13] Lesuer DR, Syn CK, Sherby OD, Wadsworth J, Lewandowski JJ, Hunt WH. Mechanical behaviour of laminated metal composites. Int Mater Rev 1996; 41(5): 169-197.

[14] Sherby OD, Lee S, Koch R, Sumi T, Wolfenstine J. Multilayered composites based on ultrahigh carbon steel and brass. Mater and Manuf Process 1990; 5(3): 363-373.

[15] Lee S, Wadsworth J, Sherby OD. Tensile properties of laminated composites based on ultrahigh carbon steel. J Compos Mater 1991; 25: 842-853.

[16] Göken M, Höppel HW. Tailoring nanostructured, graded, and particle-reinforced Al laminates by accumulative roll bonding. Adv Mater 2011; 23: 2663-2668.

[17] Emadoddin E, Tajally M, Masoumi M. Damping behavior of Al/SiCp multilayer composite manufactured by roll bonding. Mater Des 2012; 42: 334-338.

[18] Yu H, Lu C, Tieu K, Godbole A, Su L, Sun Y, Liu M, Tang D, Kong C. Fabrication of untra-thin nanostructured bimetallic foils by accumulative roll bonding and asymmetric rolling. Sci Rep 2013; 3: 2373- 
2381.

[19] Liu CY, Zhang B, Yu PF, Jing R, Ma MZ, Liu RP. Microstructures and mechanical properties of Al/Zn composites prepared by accumulative roll bonding and heat treatment. Mater Sci Eng A 2013; 580: 36-40.

[20] Carpenter JS, Vogel SC, LeDonne JE, Hammon DL, Beyerlein IJ. Bulk texture evolution of Cu-Nb nanolamellar composites during accumulative roll bonding. Acta Mater 2012; 60: 1576-1586.

[21] Ng HP, Przybilla T, Schmidt C, Lapovok R, Orlov D, Höppel H, Göken M. Asymmetric accumulative roll bonding of aluminium-titanium composite sheets. Mater Sci Eng A 2013; 576: 306-315.

[22] Kolesnikov AG, Plokhikh AI, Komisarchuk YS, Mikhaltsevich IY. A study of special features of formation of submicro- and nonosize structure in multilayer materials by the method of hot rolling. Met Sci Heat Treat 2010; 52: $273-278$.

[23] Lu H, Yuan X, Cui W, Ning X, Chen K. Rolling temperature on the SHS reaction of rolled Al/Ni reactive multilayer foils. Key Eng Mater 2012; 519: 104-107.

[24] Tabatchikova TI, Plokhikh AI, Yakovlev IL, Klyueva SY. Structure and properties of a steel-based multilayer material produced by hot pack rolling. Phys Met Metallogr 2013; 114: 580-592.

[25] Pang JC, Fan GH, Cui XP, Li AB, Geng L, Zheng ZZ, Wang QW. Mechanical properties of Ti-(SiC $/ \mathrm{Al})$ laminated composite with nano-sized TiAl3 interfacial layer synthesize by roll bonding. Mater Sci Eng A 2013; 582: 294-298.

[26] Du Y, Fan GH, Yu T, Hansen N, Geng L, Huang X. Effects of interface roughness on the annealing behaviour of laminated Ti-Al composite deformed by hot rolling. IOP Conf. Series: Materials Science and Engineering 2015; 89: 012021.

[27] Peng LM, Wang JH, Li H, Zhao JH, He LH. Synthesis and microstructural characterization of Ti-Al ${ }_{3} \mathrm{Ti}_{\text {metal- }}$ intermetallic laminate (MIL) composites. Scr Mater 2005; 52: 243-248.

[28] Hart EW. Theory of the tensile test. Acta Metall 1967; 15: 351-355.

[29] Dwivedi A, Bradley J. Mechanical response of titanium aluminide $\left(\mathrm{TiAl}_{3}\right)$. Army Research Laboratory 2010; ARL-CR-0669.

[30] Pang JC, Cui XP, Li AB, Fan GH, Geng L, Zheng ZZ, Wang QW. Effect of solid solution of Si on mechanical properties of $\mathrm{TiAl}_{3}$ based on the multi-laminated Ti-(SiC $\left./ \mathrm{Al}\right)$ composite system. Mater Sci Eng A 2013; 579: 57-63.

[31] Ashby MF. The deformation of plastically non-homogeneous materials. Philos Mag 1970; 21: 399-424. 